J. Chen · B. Tan · E. Karteris $\cdot$ S. Zervou $\cdot$ J. Digby $\cdot$

E. W. Hillhouse $\cdot$ M. Vatish $\cdot$ H. S. Randeva

\title{
Secretion of adiponectin by human placenta: differential modulation of adiponectin and its receptors by cytokines
}

Received: 18 November 2005 / Accepted: 22 December 2005 / Published online: 29 March 2006

(C) Springer-Verlag 2006

\begin{abstract}
Aims/hypothesis: Pregnancy, a state of insulin resistance, is associated with elevated levels of cytokines and profound alterations in metabolism. Serum adiponectin, an adipokine with anti-inflammatory and insulinsensitising properties, has been shown to be lower in patients with gestational diabetes mellitus, a state of greater insulin resistance than normal pregnancies. Hypothesising that the human placenta is a source of adiponectin, we investigated its expression and secretion, and the regulation by cytokines of adiponectin and its receptors. Methods: Real-time RT-PCR, radioimmunoassay, Western blotting, radioligand binding and immunofluorescent analyses were applied to demonstrate the expression, secretion and functionality of placental adiponectin. Results: Adiponectin gene expression and protein were found in the human term placenta, with expression primarily in the syncytiotrophoblast. RIA of conditioned media from explant experiments revealed that the placenta can secrete adiponectin in vitro. Addition of conditioned media to HEK-293 cells transfected with the gene for adiponectin receptor-1 (ADIPOR1) altered the phosphorylation status of extracellular signal-regulated kinase $1 / 2$ and p38 mitogen-activated protein kinase, an effect abolished after preabsorption with adiponectin antibody. Cytokines, including TNF- $\alpha$, IFN- $\gamma$, IL- 6 and leptin, differentially modulated placental adiponectin
\end{abstract}

\footnotetext{
J. Chen $\cdot$ B. Tan $\cdot$ S. Zervou $\cdot$ J. Digby $\cdot$ H. S. Randeva $(\bowtie)$ Biomedical Research Institute,

Department of Biological Sciences, University of Warwick, Gibbet Hill Road,

Coventry, CV4 7AL, UK

e-mail: hrandeva@bio.warwick.ac.uk

Tel.: +44-2476-572552

Fax: +44-2476-523701

E. Karteris · M. Vatish

Division of Clinical Science, Warwick Medical School, University of Warwick,

Coventry, UK

E. W. Hillhouse

Medical School, University of Leeds,

Leeds, UK
}

receptors as well as adiponectin gene expression and secretion. Interestingly, in placentae from women with gestational diabetes mellitus, we observed significant downregulation of adiponectin mRNA, significant upregulation of ADIPORI expression, and a non-significant increase in ADIPOR2 expression. Conclusions/ interpretation: Our results indicate that the human placenta produces and secretes adiponectin, and that adiponectin and its receptors are differentially regulated by cytokines and their expression altered in women with gestational diabetes mellitus. Collectively, our novel data suggest that adiponectin may play a role in adapting energy metabolism at the materno-fetal interface.

Keywords Adiponectin - Adiponectin receptors ·

Cytokines · Gestational diabetes mellitus ·

MAPK · Placenta

Abbreviations ADIPOR1: adiponectin receptor type 1 . ADIPOR2: adiponectin receptor type 2 .

ERK: extracellular signal-regulated kinase .

GDM: gestational diabetes mellitus · HEK-293: human embryonic kidney 293 cells · MAPK: mitogen-activated protein kinases

\section{Introduction}

Pregnancy, a state of insulin resistance, is associated with elevated levels of cytokines [1] and profound alterations in metabolism, directed towards supplying adequate nutrition for the fetus.

Adiponectin is an adipocytokine that has been shown to have anti-atherogenic, anti-inflammatory and antidiabetic roles [2]. Adiponectin is a $30-\mathrm{kDa}$ protein, composed of an $\mathrm{N}$-terminal collagen-like sequence and a C-terminal globular region, termed 'full-length adiponectin'. Proteolytic cleavage of the globular domain yields a product, termed 'globular adiponectin' [2,3], which circulates abundantly in human plasma [4]. Serum adiponectin levels are lower in insulin-resistant states [5], in contrast to the raised levels of 
other cytokines, e.g. interleukin-6 (IL-6), TNF- $\alpha$ and leptin [6]. Adiponectin orchestrates its effects by activating two seven-transmembrane domain receptors: adiponectin receptor type 1 (ADIPOR1) and adiponectin receptor 2 (ADIPOR2) [7].

Gestational diabetes mellitus (GDM), a state of increased insulin resistance, can lead to complications during pregnancy and may also increase the risk of stillbirth [8]. Recently it has been shown that elevated leptin levels were positively associated with the risk of GDM, whereas adiponectin plasma levels are reduced in women with GDM $[9,10]$. Cytokines such as TNF- $\alpha$ and IL-6, through their ability to interfere with insulin signalling, have been implicated in insulin resistance in type 2 diabetes [11].

In humans, a significant negative correlation between adipose tissue mRNA/plasma adiponectin levels and TNF- $\alpha$ has been described [12], suggesting crosstalk between adiponectin and proinflammatory cytokines [13]. Furthermore, umbilical vein serum adiponectin levels were three-fold higher than maternal serum adiponectin levels in normal pregnancy [14]. When adiponectin levels were measured in cord vein, a striking increase in plasma adiponectin concentrations with gestational age was noted [15]; concentrations at term were more than 20-fold higher compared with 24 weeks of gestation [15].

In view of these findings, we hypothesised that the human placenta might be a source of adiponectin. Therefore, we investigated both the expression and the secretion of adiponectin by the placenta, and determined whether any differences exist in the expression of adiponectin and its receptors between normal and GDM placentae. Given the reciprocal association of adiponectin with proinflammatory cytokines and the observation that these proinflammatory cytokines are raised in pregnancy, we studied the influence of cytokines on adiponectin gene expression and secretion as well as their impact on adiponectin receptor mRNA levels.

\section{Subjects, materials and methods}

Subjects and placental explant tissue culture

Placental biopsies (ten normal subjects and eight with GDM [three insulin-treated, five diet-controlled]) were obtained from women undergoing elective Caesarean sections for breech presentation, maternal request or previous Caesarean section. The demographic characteristics of the patients for this study are shown in Table 1. Informed consent was obtained from each woman and local ethical approval for the study was granted by Coventry Ethics Committee. Immediately after delivery, placental samples were snap-frozen in liquid nitrogen. Placental explant cultures, devoid of blood vessels and clots, were set up as previously described [16]. After the completion of treatments, both conditioned media and explant tissue were snap-frozen into liquid nitrogen.

\section{RNA isolation, cDNA synthesis and RT-PCR}

Total ribonucleic acid was extracted by using Ultraspec (Biotecx Laboratories, Houston, TX, USA) and reversetranscribed into cDNA as previously described [17]. For all different primer sets, 33 cycles were performed consisting of an initial denaturing step at $94^{\circ} \mathrm{C}$ for $30 \mathrm{~s}$, followed by extension at $60^{\circ} \mathrm{C}$ for $1 \mathrm{~min}$ and elongation at $72^{\circ} \mathrm{C}$ for $1 \mathrm{~min}$. Table 2 describes the primers that were used for this study.

\section{Real-time RT-PCR}

Quantitative PCR was performed on a Roche Light Cycler system (Roche Molecular Biochemicals, Mannheim, Germany). PCR reactions were performed as previously described [17]. The conditions consisted of denaturation of $95^{\circ} \mathrm{C}$ for $15 \mathrm{~s}$, followed by 40 cycles of $94^{\circ} \mathrm{C}$ for $1 \mathrm{~s}, 60^{\circ} \mathrm{C}$ for $7 \mathrm{~s}$ and $72^{\circ} \mathrm{C}$ for $12 \mathrm{~s}$, followed by melting curve analysis. For analysis, quantitative amounts of adiponectin and adiponectin receptors were standardised against the housekeeping gene $\beta$-actin (Table 2 ). As a negative control

Table 1 Data of patients participating in this study

\begin{tabular}{llll}
\hline Characteristic & Control $(n=10)$ & GDM $(n=8)$ & $p$ value \\
\hline Age (years) & 28.2 (range 20-37) & 29.3 (range 20-37) & NS \\
Systolic BP (mmHg) & $126.8(120-133)$ & $127.4(122-136)$ & NS \\
Diastolic BP (mmHg) & $67.8(60-80)$ & $66.9(62-80)$ & NS \\
Birth weight (kg) & 3.33 (range 2.7-3.85) & 3.28 (range 2.6-3.9) & NS \\
Fasting plasma glucose (nmol/1) & 4.2 (range 4.0-4.5) & $5.0($ range 4.6-5.5) & $<0.05$ \\
HbA $_{1 \mathrm{c}}(\%)$ & Not available & $7.0 \pm 0.98$ & NS \\
Gestation (weeks/days) & $38 / 6-40 / 4$ & $38 / 4-40 / 6$ & NS \\
BMI (kg/m $\left.{ }^{2}\right)$ & $25.20(20-27)$ & $25.6(20-28)$ & NS \\
Proteinuria (pluses) & Nil & Nil & NS \\
Caesarean section $(\%)$ & 100 & 100 & \\
\hline
\end{tabular}

NS Not significant 
Table 2 Primers used for RT-PCR analysis

\begin{tabular}{lll}
\hline Gene/product size & Sense primer & Antisense primer \\
\hline ADIPOR1 $(125 \mathrm{bp})$ & $5^{\prime}$-cggtggaactggctgaactg-3' & $5^{\prime}$-ccgcacctcctcctcttctt-3' \\
ADIPOR2 $(190 \mathrm{bp})$ & $5^{\prime}$-acggagttggcactcac-3' & $5^{\prime}$-gccatcgtcttgtacctcac-3' \\
Adiponectin $(124 \mathrm{bp})$ & $5^{\prime}$-ctatgatggctccactggta-3' & $5^{\prime}$-gagcatagccttgtccttct-3' \\
$\beta$-Actin $(220 \mathrm{bp})$ & $5^{\prime}$-aagagaggcatcctcaccgatgctc-3' & $5^{\prime}$-tacatggctggggtgttgaa-3' \\
\hline
\end{tabular}

for all the reactions, preparations lacking RNA or reverse transcriptase were used in place of the cDNA. RNAs were assayed from two or three independent biological replicates. The RNA levels were expressed as a ratio, using the delta-delta method for comparing relative expression results between treatments in real-time PCR [18].

\section{Immunofluorescence}

Paraffin-embedded sections of human placentae were dewaxed and dehydrated as before [19]. The primary goat polyclonal adiponectin antibody (Santa Cruz Biotechnology, Santa Cruz, CA, USA) was used at 1:100 dilution. All dilutions were made in $1 \%$ BSA in PBS. Specimens were incubated with primary antibody for $60 \mathrm{~min}$, and were then washed three times with PBS for 5 min each before incubation with anti-rabbit IgG-fluorescein isothiocyanateconjugated secondary antibody (Santa Cruz Biotechnology) for 50 min. Similarly, human embryonic kidney 293 (HEK-293)/ADIPOR1 cells were fixed and incubated with $10 \%$ BSA for $1 \mathrm{~h}$ before incubation with adipoR 1 antibody (Alpha Diagnostic International, San Antonio, TX, USA). Secondary antibody incubations and visualisation followed, as described [19].

\section{HEK-293 cell transfection}

Human embryonic kidney 293 cells were transiently transfected with the full-length ADIPORl gene (HEK293/ADIPOR1) inserted into the expression vector pcDNA 3.1 (Invitrogen, Paisley, UK) as previously described [20].

Western immunoblotting

HEK-293/ADIPOR1 cells were cultured overnight in serum-free medium, followed by treatment with adiponectin (100 nmol/1; Phoenix Peptides, Belmont, CA, USA), conditioned medium with adiponectin immunoprecipitated out of solution, and plain medium. Cells were then lysed, and proteins were separated on a SDS- $12.5 \%$ polyacrylamide gel, using methods previously described [17]. For studies on mitogen-activated protein kinases (MAPKs), HEK-293/ADIPOR1 cells were incubated with adiponectin $(100 \mathrm{nmol} / \mathrm{l})$ for $10 \mathrm{~min}$, and cell lysates were assayed for p38 and extracellular signal-regulated kinase (ERK) 1/2 phosphorylation. The primary antisera for the phosphor/ total p38 and phosphor/total ERK1/2 (Cell Signaling
Technology, Beverly, MA, USA) and adiponectin (Santa Cruz Biotechnology) were used at 1:1,000 dilution in PBS$0.1 \%$ Tween overnight at $4^{\circ} \mathrm{C}$.

Radioligand binding assay

For competitive displacement studies, HEK-293/ADIPOR1 cell membranes $(n=10 ; 100 \mu \mathrm{g}$ protein) were incubated with $1 \mathrm{nmol} / 1$ of ${ }^{125} \mathrm{I}$-adiponectin (Linco Research, St. Charles, MI, USA) in the presence or absence of unlabelled peptide $(0.1-1,000 \mathrm{nmol} / \mathrm{l})$. Nonspecific binding was measured in the presence of $1 \mu \mathrm{mol} / 1$ of unlabelled adiponectin [20].

\section{Adiponectin RIA}

After an overnight fast, venesection took place at 09.00 $10.00 \mathrm{~h}$, and samples $(n=10)$ were then centrifuged at $4^{\circ} \mathrm{C}$. Serum was stored at $-70^{\circ} \mathrm{C}$ for further analysis. Serum adiponectin concentration was determined by radioimmunoassay (Linco Research) using serum samples diluted 1:600 in assay buffer. The concentration of adiponectin in tissue culture media from placental explants was determined using $100 \mu \mathrm{l}$ of undiluted medium for each duplicate. The lowest level of human adiponectin detected in this assay was $1 \mathrm{ng} / \mathrm{ml}$. The intra-assay variation was $<6 \%$.

\section{Statistical analysis}

Data are shown as the mean \pm SEM of each measurement. ANOVA was performed to analyse measurements of the intensity of immunoreactive staining using a scanning densitometer (Scion Image; Scion, Frederick, MD, USA). Student's $t$-test was employed to calculate the significance of differences in the means between the different groups. A $p$ value $<0.05$ was considered to be significant.

\section{Results}

Expression of adiponectin in human placenta

Using RT-PCR analysis, we detected adiponectin mRNA in human term placenta, using adipose tissue as a positive control (Fig. 1a). Subsequent sequencing of the PCR products confirmed the gene identity. Using real-time RT- 
PCR, we showed that adiponectin mRNA was expressed at a significantly higher $(p<0.01)$ level in s.c. adipose tissue compared with normal placenta from the same patients (Fig. 1b). Using Western blotting analysis, we also showed that these changes were also reflected at the protein level (Fig. 1b, insert).

Immunofluorescence analysis of human term placentae revealed that immunoreactive adiponectin staining was localised almost exclusively in the syncytiotrophoblast. We found no apparent expression in the cytotrophoblast and little staining was evident within the placental blood vessels (Fig. 1c, I). Adipose tissue was also used as a positive control (Fig. 1c, II). Negative serum controls confirmed the specificity of the positive immunoreactive staining (Fig. 1c, III, IV). Identical results were obtained from four independent experiments.

\section{Secretion of placental adiponectin}

Western blot analysis of conditioned media from placental explants $(4 \mathrm{~h})$ demonstrated the presence of adiponectin protein, with a molecular weight (around $33 \mathrm{kDa}$ ) identical to that found for placental $(100 \mu \mathrm{g})$ and adipose tissue lysates $(10 \mu \mathrm{g})$; there was no apparent protein expression of adiponectin detected in culture medium alone, whereas adiponectin was detectable in conditioned medium (Fig. 1d). Furthermore, RIA confirmed secretion of adiponectin in vitro from conditioned medium $(n=10$; $100 \pm 20 \mathrm{ng} / \mathrm{ml}$ ), whereas in culture medium alone there was no detectable adiponectin present. Diluted serum from the same control subjects $(n=10)$ was used as a positive control (Fig. 1e). $\mathbf{a}$

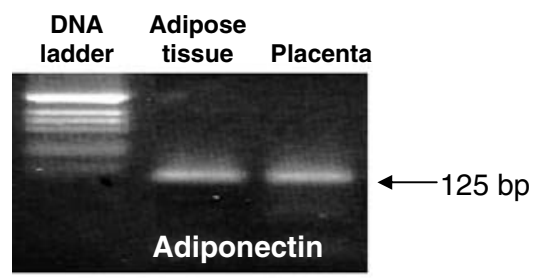

c
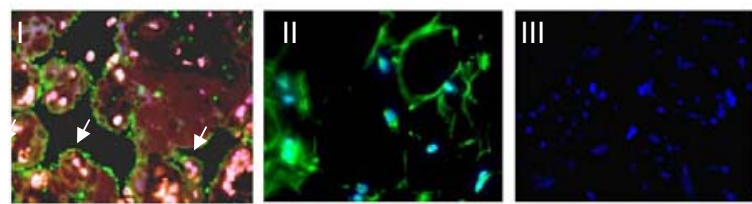

d

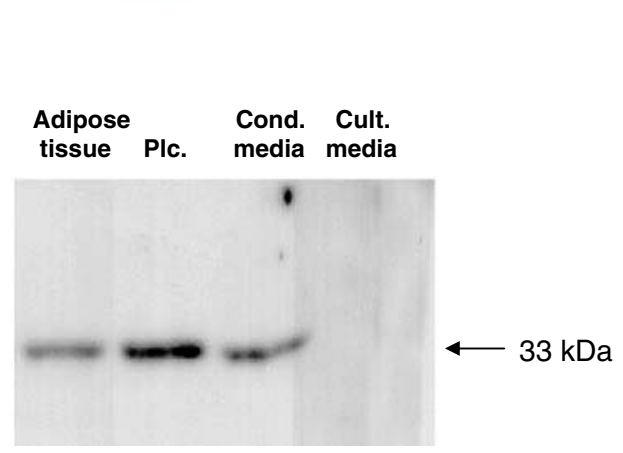

Fig. 1 a RT-PCR analysis revealed expression of adiponectin in human placentae (125 bp). Adipose tissue was used as a positive control. b Adiponectin mRNA was significantly more abundant in subcutaneous (SC) adipose tissue than in normal placenta $(\mathrm{Plc})$. ${ }^{* *} p<0.01$. Adiponectin protein levels (insert) were also greater in subcutaneous adipose tissue than in normal placenta. c Immunofluorescence analysis using a specific antibody demonstrated localisation of adiponectin primarily in syncytiotrophoblasts (small arrows, I) and some scattered expression around blood vessels. Adipose tissue was used as a positive control (II). Negative serum controls confirmed the specificity of the positive immunoreactive staining
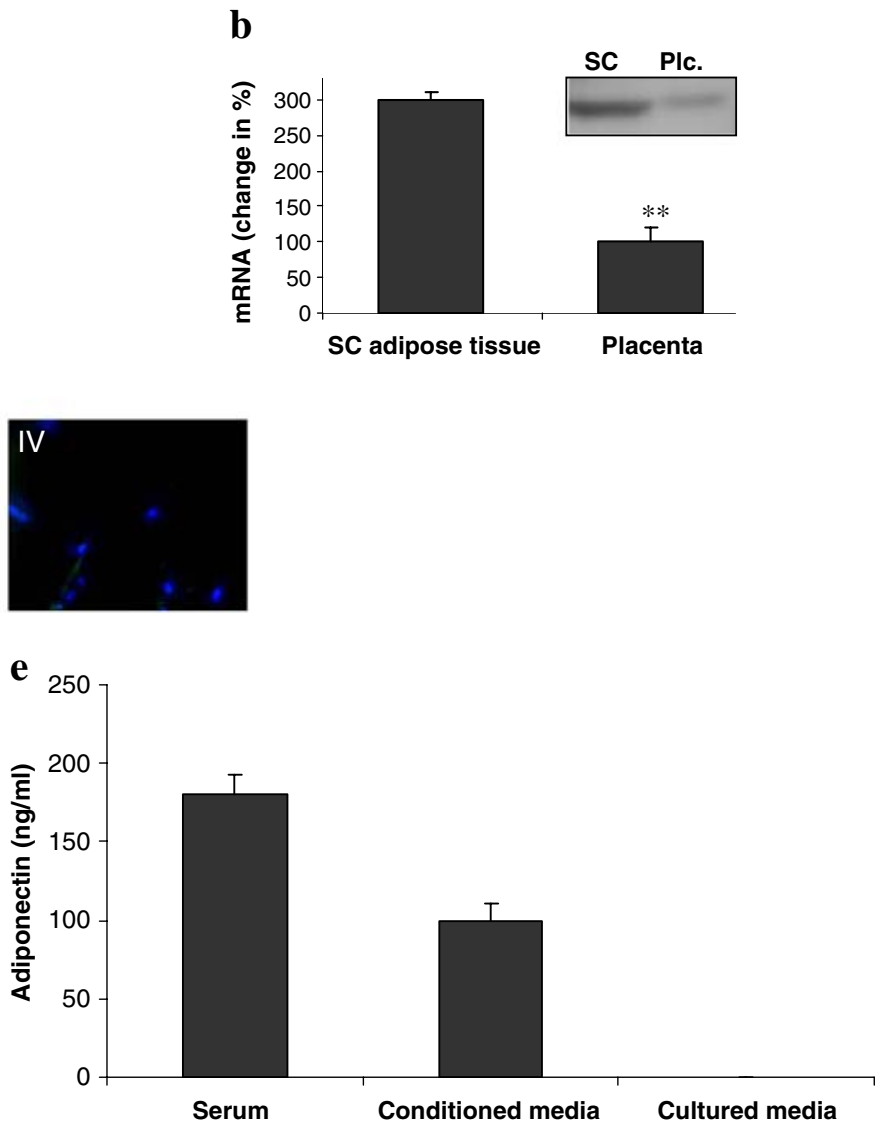

(III, IV). Identical results were obtained from four independent experiments. Original magnification, $\times 400$. d Western blotting using the same antibody confirmed the detection of adiponectin in human placental (Plc) lysates $(100 \mu \mathrm{g})$ and in conditioned (Cond.) but not culture (Cult.) medium. It appeared as a single band with apparent molecular weight $33 \mathrm{kDa}$. Adipose tissue $(10 \mu \mathrm{g})$ was also used as a positive control. e Data analysis from RIA studies confirmed secretion of adiponectin from placental explants $(n=10)$ in vitro (conditioned medium, $100 \pm 20 \mathrm{ng} / \mathrm{ml}$ ), whereas in culture medium alone adiponectin was not detected. Serum $(n=10)$ was used as a positive control 
Expression of adiponectin and its receptors in GDM

Using real-time PCR and values standardised against $\beta$ actin, we showed that in GDM placentae $(n=8)$ there was significant downregulation of placental adiponectin mRNA levels compared with normal $(n=10)$, as can be seen from the delay in the amplification of the gene (Fig. 2a). Statistical analysis of these data revealed that this downregulation was significant $(* * * p<0.001)$ (Fig. 2b). We also

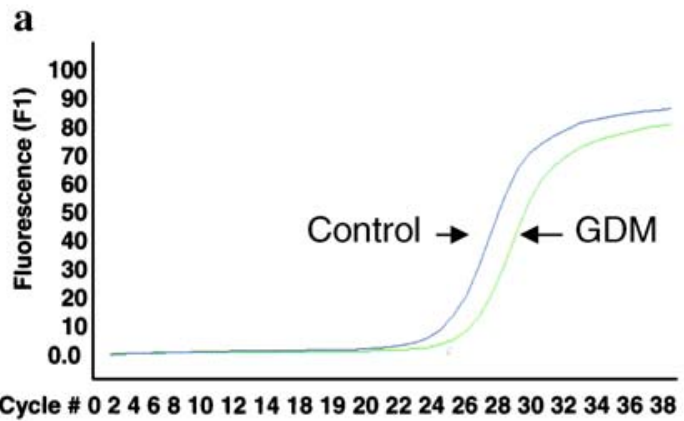

c

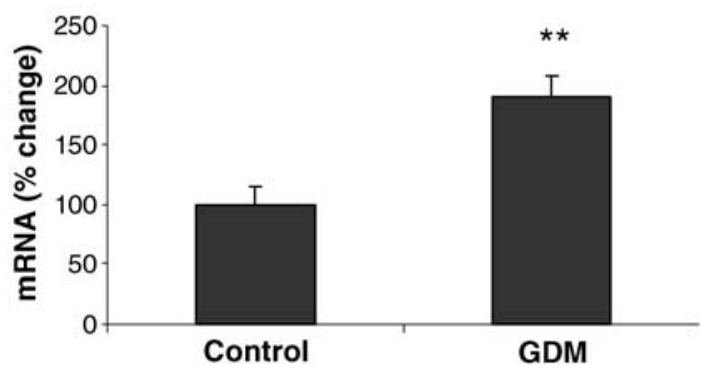

e
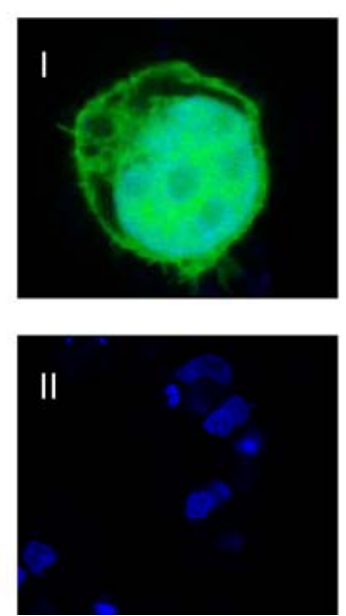

Fig. 2 a There was significant downregulation of adiponectin mRNA in GDM placenta $(n=8)$ compared with controls $(n=10)$, as can be seen from the delay in amplification (intercept cycle). b Summarised data showing changes in GDM vs controls for the adiponectin gene. ${ }^{* * *} p<0.001$. c A significant increase $(* * p<0.01)$ was detected in ADIPOR $1 \mathrm{mRNA}$ in GDM placenta $(n=8)$ compared with controls $(n=10)$. d The difference in ADIPOR 2 mRNA in GDM placenta $(n=8)$ compared with controls $(n=10)$ was not significant $(p>0.05)$. e Immunofluorescence analysis using a specific antibody used real-time RT-PCR to assess the expression of ADIPOR 1 and ADIPOR2 in GDM placenta. We showed that there was a significant increase in $A D I P O R 1 \mathrm{mRNA}$ $(* * p<0.01$; Fig. 2c) in GDM placenta $(90 \%$ increase compared with normal), whereas no significant upregulation in the expression of ADIPOR 2 was detected between the two groups (Fig. 2d).

b

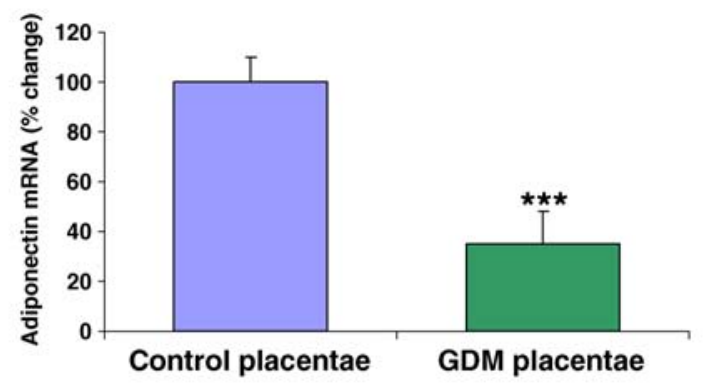

d

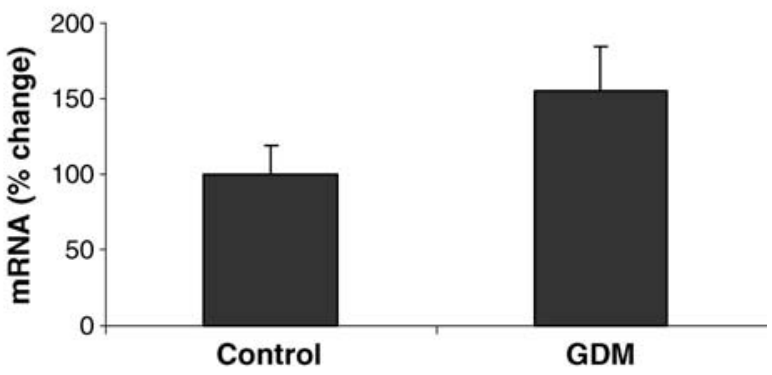

f

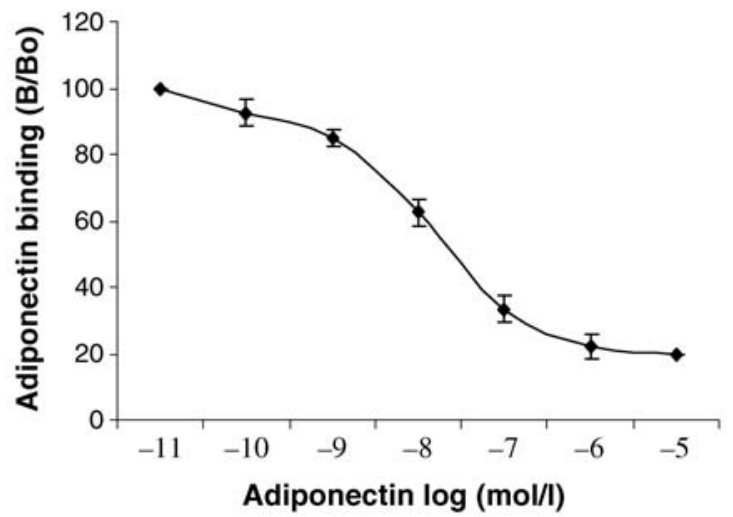

confirmed adequate expression of ADIPOR1 in HEK-293 cells. ADIPOR1 appears to be localised on the membrane of the cells, in accordance with its seven-transmembrane configuration (I). Preabsorption with blocking peptide for ADIPOR 1 confirmed the specificity of the positive immunoreactive staining (II). Identical results were obtained from four independent experiments. Original magnification, $\times 400$. f Displacement curves for binding of ${ }^{925} \mathrm{I}-$ adiponectin to HEK-293/ADIPOR1 membranes. Each point is the mean of four estimations 
Modulation of p38 and ERK1/2 MAP kinases by placental adiponectin

Following the detection of placental adiponectin, we used full-length adiponectin not to assess the biofunction of adiponectin receptors but to see whether the secreted placental adiponectin had affinity for the ADIPOR1 receptors. We did this by measuring its effect on the phosphorylation of MAPKs in HEK-293/ADIPOR1 cells. For this study, full-length adiponectin was used as a control.

Prior to this, we demonstrated the presence of functional ADIPOR1 in HEK-293 cells by using immunofluorescence and displacement studies. Immunofluorescent analysis, using a specific ADIPOR1 antibody, demonstrated expression of the receptor on the cell surface of HEK-293/ ADIPOR1 cells, in accordance with its proposed localisation as a seven-transmembrane domain receptor (Fig. 2e, I). Preabsorption with blocking peptide for ADIPOR1 confirmed the specificity of the positive immunoreactive staining (Fig. 2e, II). Identical results were obtained from four independent experiments. The presence of functional ADIPOR1 receptors in HEK-293 cells was further confirmed by binding displacement studies. Human 'cold' adiponectin was able to displace its respective radiolabelled ligand from its binding sites in a concentrationdependent manner in HEK-293/ADIPOR1 cells (Fig. 2f).

Treatment of HEK-293/ADIPOR1 cells $(n=10)$ with adiponectin induced significant $(p<0.01)$ downregulation of phosphorylation of both $\mathrm{p} 38$ and ERK1/2 (Fig. 3a,b). This effect appeared to be dose-dependent (data not shown), with maximal effect at $100 \mathrm{nmol} / \mathrm{l}$. Furthermore, this effect was maximal after $10 \mathrm{~min}$ of treatment and returned to basal levels after $45 \mathrm{~min}$ of treatment (data not shown). Despite decreased levels of both phospho-p38 and phosphoERK1/2, the total amounts of both MAPKs were unchanged (Fig. 3a,b). Interestingly, conditioned medium exerted a very similar effect on p38 and ERK1/2 phosphorylation. However, when adiponectin was immunoprecipitated out of the conditioned medium, the adiponectin-free medium failed to alter the phosphorylation status of both MAPKs, indicating that the peptide exerting this specific effect was indeed placentally secreted adiponectin (Fig. 3a,b).

\section{Modulation of placental adiponectin by cytokines}

Placental explants from uncomplicated pregnancies $(n=10)$ were treated with TNF- $\alpha$, IFN- $\gamma$, TNF- $\alpha+$ IFN- $\gamma$, IL- 6 or leptin at a concentration of $100 \mathrm{nmol} / \mathrm{l}$ for 4 and $24 \mathrm{~h}$ (Fig. 4).

Treatment of placental explants (Fig. 4a) with TNF- $\alpha$ or IFN- $\gamma$ for $4 \mathrm{~h}$ did not exert any significant effect at the mRNA level, whereas at $24 \mathrm{~h}$ TNF- $\alpha$ reduced and IFN- $\gamma$ induced adiponectin mRNA $(p<0.05)$. Interestingly, a combination of TNF- $\alpha$ and IFN- $\gamma$ led to greater downregulation of adiponectin mRNA levels at both $4 \mathrm{~h}(40 \%$ below basal; $p<0.05)$ and $24 \mathrm{~h}(95 \%$ below basal; $p<0.01)$. IL-6, at both time points, significantly reduced adiponectin a

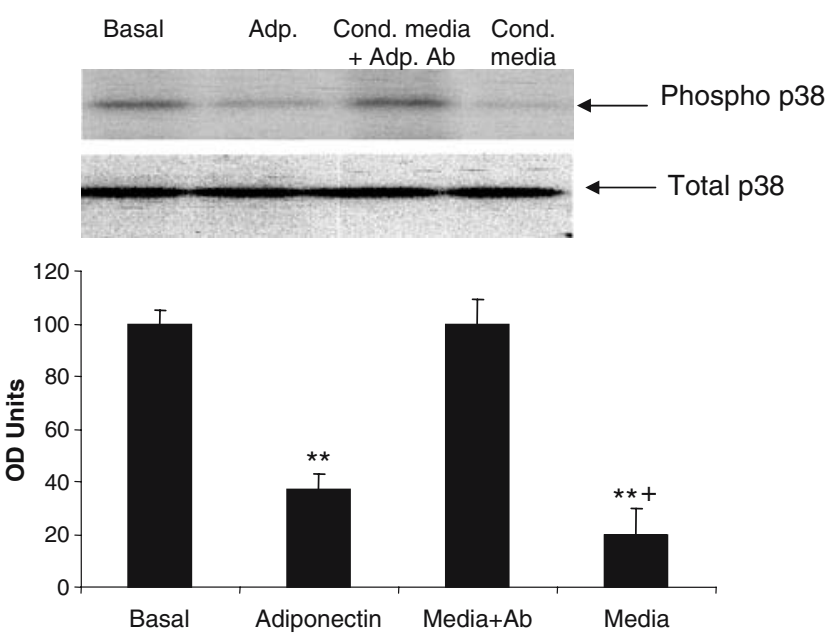

b

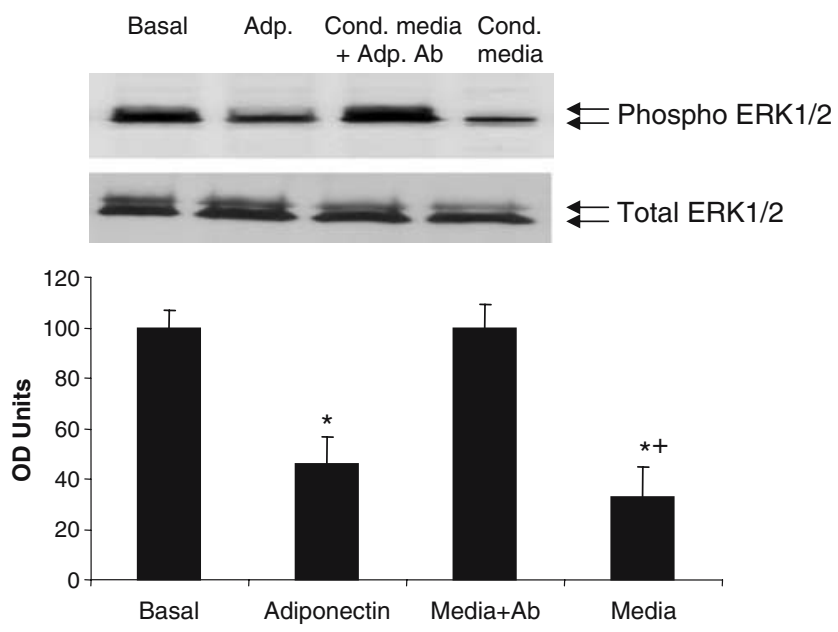

Fig. 3 a Placental adiponectin suppresses the phosphorylation of p38 MAPK in HEK293/ADIPOR1 cells. Cells were treated with adiponectin (Adp.) $(100 \mathrm{nmol} / \mathrm{l}$ for $10 \mathrm{~min})$, conditioned medium with adiponectin immunoprecipitated out of solution (Cond. med.+Adp. Ab) and conditioned medium. The same samples were immunoblotted with antibody for total $\mathrm{p} 38$ as a control. Values are mean \pm SEM of ten experiments. ${ }^{* *} p<0.01$ compared with basal (no supplement), ${ }^{+} p<0.05$ compared with adiponectin-deficient tissue culture medium. b Placental adiponectin suppresses the phosphorylation of ERK1/2 MAPK in HEK293/ADIPOR1 cells. The same samples were immunoblotted with antibody for total ERK1/2 as a control. Values are mean \pm SEM of ten experiments. ${ }^{*} p<0.05$ compared with basal (no supplement), $+p<0.05$ compared with adiponectin-free conditioned medium

mRNA levels $(4 \mathrm{~h}, 72 \%, p<0.05 ; 24 \mathrm{~h}, 85 \%, p<0.01)$ compared with basal. Of interest, however, treatment with leptin for $4 \mathrm{~h}$ induced adiponectin mRNA (70\% above basal, $p<0.05$ ), whereas at $24 \mathrm{~h}$ adiponectin mRNA levels were dramatically reduced $(90 \%$ below basal, $p<0.01)$.

Further to the mRNA changes, these cytokines also altered the secretion of placental adiponectin into culture medium (Fig. 4b). After $4 \mathrm{~h}$ of incubation, all cytokines reduced the secretion of placental adiponectin $(p<0.01)$. After $24 \mathrm{~h}$ of incubation, the pattern of adiponectin 
Fig. 4 a Effects of cytokines at 4 and $24 \mathrm{~h}$ on placental adiponectin mRNA assessed by real-time $\mathrm{PCR}$. Values are mean \pm SEM of ten experiments. ${ }^{*} p<0.05$; $* * p<0.01$ compared with no supplement (NS).

b Effects of cytokines at 4 and $24 \mathrm{~h}$ on adiponectin secretion from placental explants, assessed using RIA. Values are means \pm SEM of ten experiments. $* p<0.05, * * p<0.01$ compared with NS
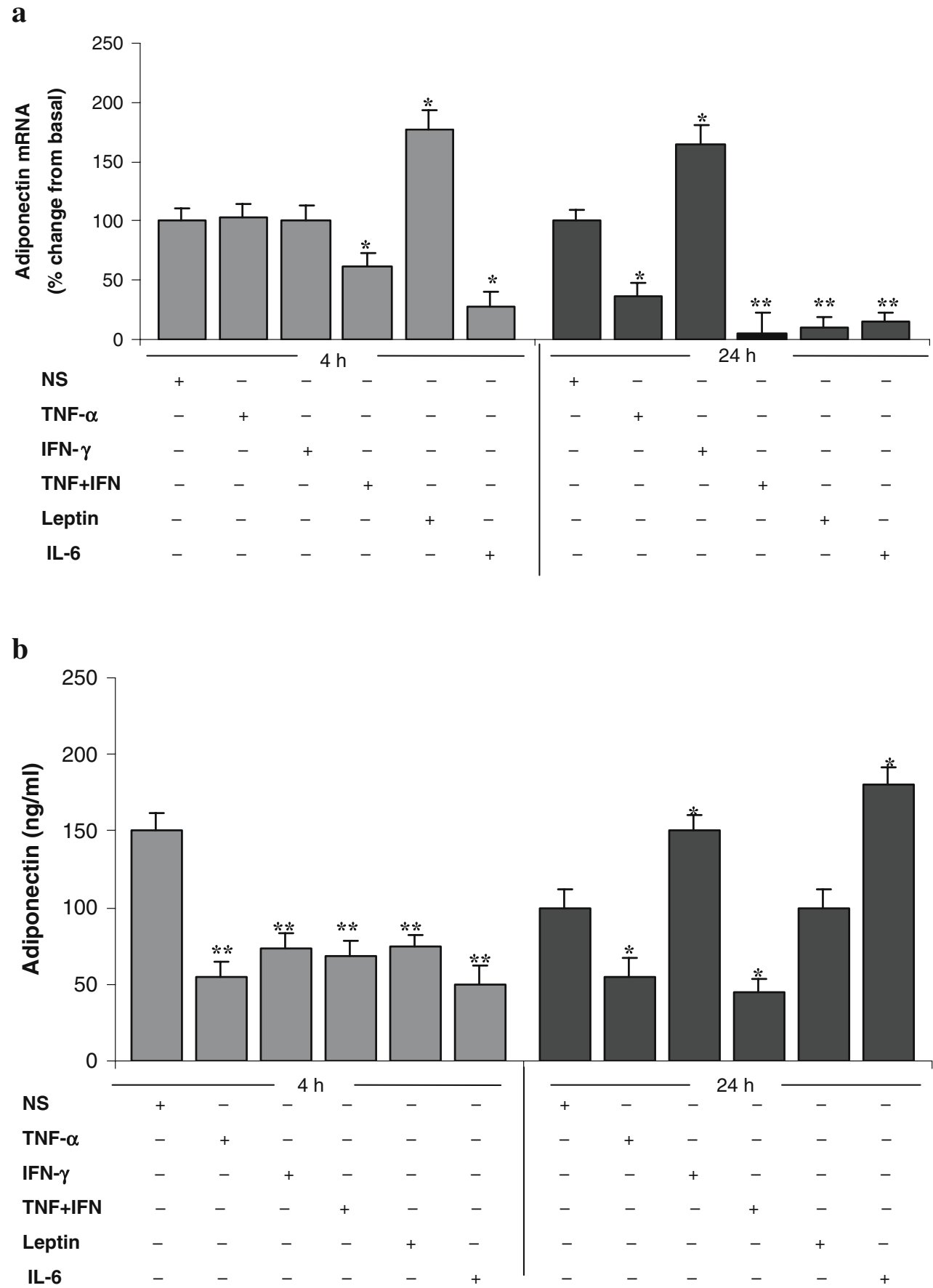

secretion mirrored that seen at the mRNA level, with the exception that leptin did not exert any significant effect, while IL-6 increased adiponectin $(80 \%$ above basal; $p<0.05)$.

Modulation of placental adiponectin receptors by cytokines

We used the same mRNA from normal placental explants $(n=10)$, treated with various cytokines, to assess their effects on both ADIPOR1 and ADIPOR2 mRNA (Fig. 5).
Treatment of placental explants with TNF- $\alpha$ or IFN- $\gamma$ or a combination of both significantly induced ADIPORI mRNA at both 4 and $24 \mathrm{~h}$ (Fig. 5a). Interestingly, a combination of TNF- $\alpha$ and IFN- $\gamma$ at $4 \mathrm{~h}$ led to greater upregulation of ADIPOR1 mRNA levels at $4 \mathrm{~h}$ compared with $24 \mathrm{~h}$. Similarly, IL-6 and leptin, at both time points, significantly reduced ADIPORl mRNA levels $(4 \mathrm{~h}$, $p<0.01 ; 24 \mathrm{~h}, p<0.05)$ compared with the basal condition (Fig. 5a).

Interestingly, treatment of placental explants with TNF- $\alpha$ or IFN- $\gamma$ or a combination of both did not have any apparent effect on adipoR 2 at $4 \mathrm{~h}$ of treatment, whereas 
Fig. 5 Effects of cytokines at 4 and $24 \mathrm{~h}$ on (a) placental $A D I P O R 1 \mathrm{mRNA}$ and

(b) ADIPOR2 mRNA assessed by real-time PCR. Values are mean $\pm \mathrm{SEM}$ of ten experiments. $* p<0.05, * * p<0.01$ compared with no supplement (NS) a

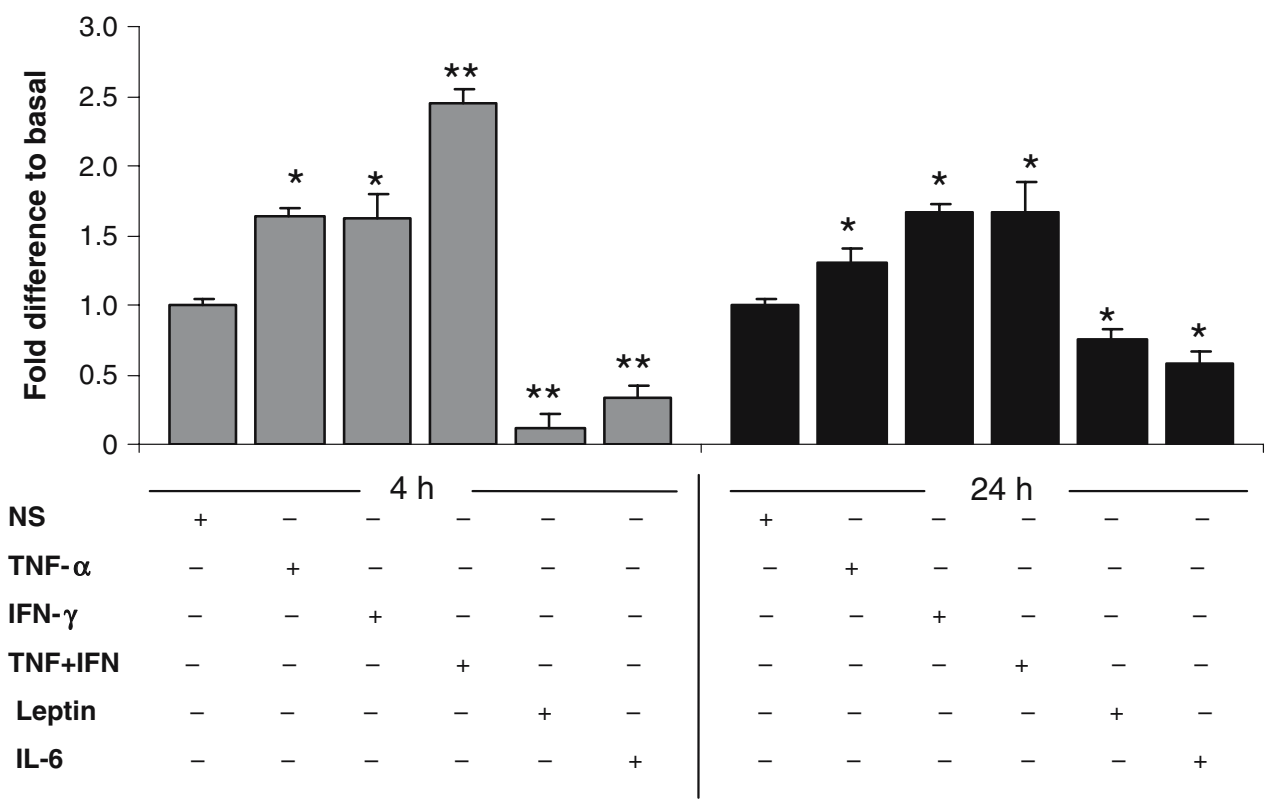

b

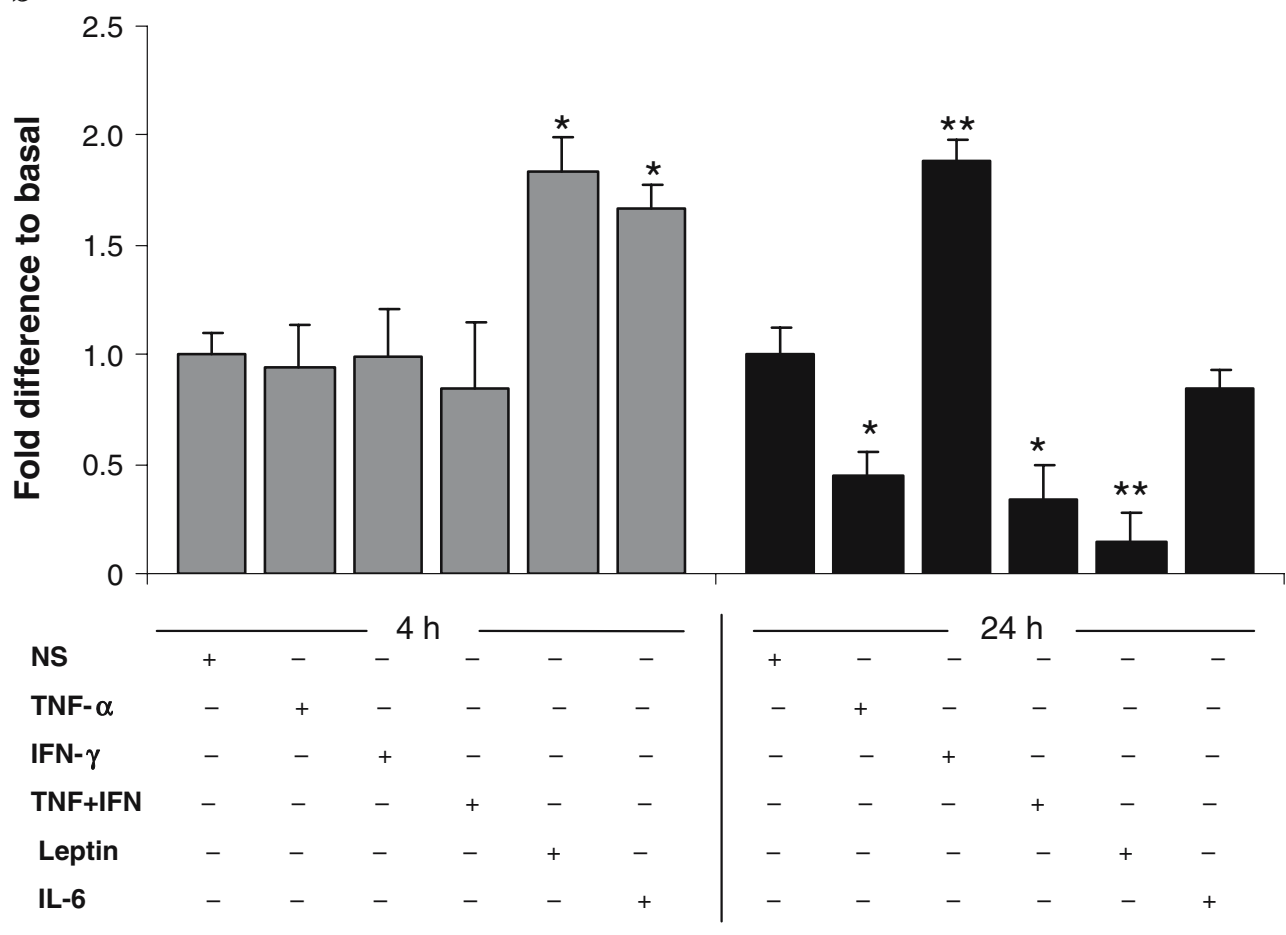

at $24 \mathrm{~h}$ changes in $A D I P O R 2$ mRNA mirrored those of adiponectin (Fig. 5b). TNF- $\alpha$ significantly $(p<0.05)$ downregulated ADIPOR 2 mRNA and IFN- $\gamma$ significantly $(p<0.01)$ upregulated ADIPOR2, whereas a combination of both reduced ADIPOR2 mRNA levels $(p<0.05)$. Moreover, both leptin and IL-6 significantly induced $(p<0.05)$ $A D I P O R 2$ mRNA at $4 \mathrm{~h}$, whereas at $24 \mathrm{~h}$ leptin decreased ADIPOR2 mRNA and IL-6 had no effect on its gene expression (Fig. 5b).

\section{Discussion}

In the present study, we demonstrate the production of adiponectin in the human placenta, and the presence of both types of adiponectin receptor. Furthermore, we provide novel data showing that the human placenta is able to secrete adiponectin (in an explant system) in an in vitro model. Expression of adiponectin was confined to the syncytiotrophoblast, a site where numerous placental hormones are produced, e.g. chorionic gonadotrophin 
[21], placental lactogen [21], corticotropin releasing factor [22] and urocortin [23]. Syncytiotrophoblast also expresses leptin [24] and resistin [25], two other adipokines, suggesting an important endocrine and metabolic role of the placenta. Proinflammatory cytokines, which are raised in pregnancy and contribute to the insulin-resistant state in pregnancy, differentially modulated placental adiponectin receptors as well as adiponectin expression and secretion.

Recently, it has been shown that plasma adiponectin levels are reduced in pregnancy-induced insulin resistance $[9,10]$; in addition, plasma adiponectin correlates negatively with TNF- $\alpha$ and leptin [9]. Based on our data and the knowledge that cytokines are elevated during pregnancy [1], it is attractive to speculate that, during pregnancyinduced insulin resistance, cytokines exert a regulatory role in the secretion of placental adiponectin. Interestingly, we noted significantly lower adiponectin gene expression in GDM placenta, which may potentially contribute to the relatively lower plasma adiponectin levels seen in GDM subjects [10], known to have raised cytokines.

In accordance with a previous study in which cytokines were shown to influence the expression and secretion of adiponectin [26], we report similar effects on placental adiponectin. Interestingly, in isolation TNF- $\alpha$ reduced and IFN- $\gamma$ induced adiponectin, but in combination they downregulated both mRNA expression and secretion of adiponectin by the greatest magnitude, when compared with the effects of TNF- $\alpha$ and IFN- $\gamma$ alone. The molecular mechanism(s) for these effects is not entirely clear. What is evident from other biological systems, including human monocytes [27], rat brain [28] and murine macrophages [29], for example, is that IFN- $\gamma$ influences the effect of TNF- $\alpha$, in some cases being synergistic. Conversely, similar treatment of $\mathrm{C}_{2} \mathrm{C}_{12}$ myotubes with a combination of TNF- $\alpha$ and IFN- $\gamma$ induced adiponectin mRNA expression over $24 \mathrm{~h} \mathrm{[26],} \mathrm{suggesting} \mathrm{that} \mathrm{the} \mathrm{adiponectin} \mathrm{gene}$ can or may be modulated in a tissue-specific fashion. Moreover, we found that treatment of placental explants with IL-6 resulted in a dramatic decrease in mRNA but a significant increase in adiponectin secretion at $24 \mathrm{~h}$. The precise reason why there is this disparity between mRNA and secreted levels is not known but may represent either a form of negative feedback or differences in turnover. Additionally, leptin induced adiponectin at the mRNA level at $4 \mathrm{~h}$ and decreased it at $24 \mathrm{~h}$, but significantly reduced secretion in vitro only at $4 \mathrm{~h}$. The reason IL- 6 and leptin exert these differential effects on mRNA and adiponectin secretion, an observation noted with each placenta, may be the fact that leptin induces IL-6 release in term trophoblast cells [30], which in turn can exert an inhibitory effect, influencing adiponectin secretion.

We also provide novel data on the presence of both types of adiponectin receptor in the human placenta and the influence of cytokines on their mRNA expression. Placental explants treated with TNF- $\alpha$ or IFN- $\gamma$ or a combination of TNF- $\alpha$ with IFN- $\gamma$ significantly induced ADIPOR1 mRNA at both 4 and $24 \mathrm{~h}$, the two cytokines having a synergistic effect at $4 \mathrm{~h}$, whereas IL-6 and leptin downregulated ADIPOR1 mRNA. Moreover, changes in ADIPOR2
mRNA mirrored those in adiponectin at $24 \mathrm{~h}: \mathrm{TNF}-\alpha$ significantly down regulated ADIPOR2 mRNA and IFN- $\gamma$ significantly induced $A D I P O R 2$, whereas a combination of TNF- $\alpha$ with IFN- $\gamma$ reduced ADIPOR 2 gene expression.

It appears therefore that metabolic changes can influence adiponectin receptor expression in the human placenta, and that the GDM placenta has a significantly raised ADIPORI level. Some of these changes may be explained by adiponectin's paracrine effects on these receptors. However, we feel that cytokines may also influence the adiponectin receptors directly, as there are differences in ADIPOR 1 and ADIPOR 2 mRNA expression at $24 \mathrm{~h}$ that cannot be explained simply by fluctuations in placental adiponectin. Collectively, our data open up the interesting concept that these receptors may have different functions in the placenta.

During the preparation of this paper, Caminos et al. demonstrated the presence of adiponectin mRNA and only ADIPOR2 in the human and rat placenta [31]. However, our study is the first to show: (1) both expression and secretion of adiponectin from the human placenta; (2) the presence of both types of adiponectin receptor, providing insight into the modulation of both adiponectin receptors and adiponectin expression/secretion by cytokines; and (3) lower levels of adiponectin mRNA and higher levels of ADIPOR1 in GDM placentae. We also provide evidence that the secreted placental adiponectin is functional.

In the present study, immunoreactive placental adiponectin, present in the conditioned medium, altered the phosphorylation status of p38 and ERK1/2 MAPK in HEK-293 cells transfected with ADIPOR1, confirming the presence of bioactive adiponectin. Our data demonstrate for first time that placental adiponectin can suppress MAPK phosphorylation (ERK1/2 and p38) in a wellcontrolled environment. These MAPKs control many cellular events, from complex programmes such, as cell differentiation, proliferation and death, to the short-term changes required for homeostasis and acute hormonal responses. In the human placenta, the ERK1/2 and p38 pathways are essential for the initiation of trophoblast differentiation [32], implantation and placentation [33, 34]. It is attractive, therefore, to speculate that placental adiponectin acting in an autocrine/paracrine manner might influence placental development by altering the phosphorylation status of MAPKs. Further work is needed to investigate these MAPKs in placental explant systems.

A limitation of our study is that the results of our explant studies cannot be extrapolated directly to the whole fetoplacental unit. However, the study does raise interesting questions on the potential mechanisms occurring in the placental microenvironment. On the other hand, the strengths of our study are that our the identification of adiponectin in the syncytiotrophoblast is undeniable, and that secretion (albeit in vitro) is significant and regulated by cytokines, the latter being implicated in the insulinresistant state during pregnancy. Future studies should make use of placental cell lines that might express adiponectin and adiponectin receptors endogenously to dissect further their signalling properties, including the 
dichotomy between the secretion and expression of adiponectin with IL-6 and leptin. With regard to GDM placentae compared with controls, future studies are needed to investigate not only the secretion of placental adiponectin and its regulation by cytokines in an explant system, but also any differences in p38 and ERK1/2MAPK that may exist, given the higher miscarriage rates in diabetic pregnancies $[35,36]$. Moreover, it will be interesting to investigate further what effect these cytokines have on adiponectin and its receptors in placentae, not only in GDM but also in those with type-1 diabetes mellitus, whose offspring are known to be at increased risk of developing obesity, impaired glucose tolerance and type 2 diabetes mellitus.

In conclusion, we provide novel evidence that the human placenta secretes adiponectin. Our novel data also suggest that adiponectin and its receptors are modulated by cytokines. Moreover, in GDM placentae the expression of adiponectin is lower, whereas adiponectin receptors are upregulated. It therefore appears that placental adiponectin, acting in an autocrine/paracrine fashion, might play an important role at the maternal-fetal interface and contribute to glucose metabolism during pregnancy.

Acknowledgements This work was supported by Research Grants to H. S. Randeva from the General Charities of the City of Coventry. $\mathrm{J}$. Chen is a British Heart Foundation Research Fellow. M. Vatish and H. S. Randeva should be considered joint last authors.

\section{References}

1. Seely EW, Solomon CG (2003) Insulin resistance and its potential role in pregnancy-induced hypertension. J Clin Endocrinol Metab 88:2393-2398

2. Pajvani UB, Du X, Combs TP et al (2003) Structure-function studies of the adipocyte-secreted hormone Acrp30/adiponectin. Implications for metabolic regulation and bioactivity. J Biol Chem 278:9073-9085

3. Fruebis J, Tsao TS, Javorschi S et al (2001) Proteolytic cleavage product of $30-\mathrm{kDa}$ adipocyte complement-related protein increases fatty acid oxidation in muscle and causes weight loss in mice. Proc Natl Acad Sci USA 98:2005-2010

4. Tsao TS, Tomas E, Murrey HE et al (2003) Role of disulfide bonds in Acrp30/adiponectin structure and signaling specificity. Different oligomers activate different signal transduction pathways. Biol Chem 278:50810-50817

5. Kern PA, Ranganathan S, Li C, Wood L, Ranganathan G (2001) Adipose tissue tumor necrosis factor and interleukin-6 expression in human obesity and insulin resistance. Am J Physiol Endocrinol Metab 280:745-751

6. Arita Y, Kihara S, Ouchi N et al (1999) Paradoxical decrease of an adipose-specific protein, adiponectin, in obesity. Biochem Biophys Res Commun 257:79-83

7. Yamauchi T, Kamon J, Ito Y et al (2003) Cloning of adiponectin receptors that mediate antidiabetic metabolic effects. Nature 423:762-976

8. Kirwan JP, Hauguel-De Mouzon S, Lepercq J et al (2002) TNFalpha is a predictor of insulin resistance in human pregnancy. Diabetes 51:2207-2213

9. Cseh K, Baranyi E, Melczer Z, Kaszas E, Palik E, Winkler G (2004) Plasma adiponectin and pregnancy-induced insulin resistance. Diabetes Care 27:274-275
10. Ranheim T, Haugen F, Staff AC, Braekke K, Harsem NK, Drevon CA (2004) Adiponectin is reduced in gestational diabetes mellitus in normal weight women. Acta Obstet Gynecol Scand 83:341-347

11. Lappas M, Permezel M, Rice GE (2004) Release of proinflammatory cytokines and 8-isoprostane from placenta, adipose tissue, and skeletal muscle from normal pregnant women and women with gestational diabetes mellitus. J Clin Endocrinol Metab 89:5627-5633

12. Kern PA, Di Gregorio GB, Lu T, Rassouli N, Ranganathan G (2003) Adiponectin expression from human adipose tissue: relation to obesity, insulin resistance, and tumor necrosis factoralpha expression. Diabetes 52:1779-1785

13. Kappes A, Loffler G (2000) Influences of ionomycin, dibutyryl-cycloAMP and tumour necrosis factor-alpha on intracellular amount and secretion of apM1 in differentiating primary human preadipocytes. Horm Metab Res 32:548-554

14. Chan TF, Yuan SS, Chen HS et al (2004) Correlations between umbilical and maternal serum adiponectin levels and neonatal birthweights. Acta Obstet Gynecol Scand 83:165-169

15. Karte Kajantie E, Hytinantti T, Hovi P, Andersson S (2004) Cord plasma adiponectin: a 20-fold rise between 24 weeks gestation and term. J Clin Endocrinol Metab 89:4031-4036

16. Karteris E, Grammatopoulos D, Randeva H, Hillhouse EW (2000) Signal transduction characteristics of the corticotropinreleasing hormone receptors in the feto-placental unit. J Clin Endocrinol Metab 85:1989-1996

17. Karteris E, Goumenou A, Koumantakis E, Hillhouse EW, Grammatopoulos DK (2003) Reduced expression of corticotropin-releasing hormone receptor type-1 alpha in human preeclamptic and growth-restricted placentas. J Clin Endocrinol Metab 88:363-370

18. Pfaffl MW (2001) A new mathematical model for relative quantification in real-time RT-PCR. Nucleic Acids Res 29:e45

19. Karteris E, Grammatopoulos D, Dai Y et al (1998) The human placenta and fetal membranes express the corticotropin-releasing hormone receptor 1alpha (CRH-1alpha) and the CRH-C variant receptor. J Clin Endocrinol Metab 83:1376-1379

20. Chen J, Randeva HS (2004) Genomic organization of mouse orexin receptors: characterization of two novel tissue-specific splice variants. Mol Endocrinol 18:2790-2804

21. Richards RG, Hartman SM, Handwerger S (1994) Human cytotrophoblast cells cultured in maternal serum progress to a differentiated syncytial phenotype expressing both human chorionic gonadotropin and human placental lactogen. Endocrinology 135:321-329

22. Robinson BG, Emanuel RL, Frim DM, Majzoub JA (1998) Glucocorticoid stimulates expression of corticotropin-releasing hormone gene in human placenta. Proc Natl Acad Sci USA 85:5244-5248

23. Clifton VL, Gu Q, Murphy VE, Schwartz J, Madsen G, Smith R (2000) Localization and characterization of urocortin during human pregnancy. Placenta 21:782-788

24. Masuzaki H, Ogawa Y, Sagawa N et al (1997) Nonadipose tissue production of leptin: leptin as a novel placenta-derived hormone in humans. Nat Med 3:1029-1033

25. Yura S, Sagawa N, Itoh H et al (2003) Resistin is expressed in the human placenta. J Clin Endocrinol Metab 88:1394-1397

26. Delaigle AM, Jonas JC, Bauche IB, Cornu O, Brichard SM (2004) Induction of adiponectin in skeletal muscle by inflammatory cytokines: in vivo and in vitro studies. Endocrinology 145:5589-5597

27. Donnelly RP, Freeman SL, Hayes MP (1995) Inhibition of IL10 expression by IFN-gamma up-regulates transcription of TNF-alpha in human monocytes. J Immunol 155:1420-1427

28. De Simoni MG, Terreni L, Chiesa R, Mangiarotti F, Forloni GL (1997) Interferon-gamma potentiates interleukin (IL)-6 and tumor necrosis factor-alpha but not IL-1beta induced by endotoxin in the brain. Endocrinology 138:5220-5226 
29. Suk K, Somers SD, Erickson KL (1993) Regulation of murine macrophage function by IL-4: IL-4 and IFN-gamma differentially regulate macrophage tumoricidal activation. Immunology 80:617-624

30. Cameo P, Bischof P, Calvo JC (2003) Effect of leptin on progesterone, human chorionic gonadotropin, and interleukin- 6 secretion by human term trophoblast cells in culture. Biol Reprod 68:472-477

31. Caminos JE, Nogueiras R, Gallego R et al (2005) Expression and regulation of adiponectin and receptor in human and rat placenta. J Clin Endocrinol Metab 90:4276-4286

32. Daoud G, Amyot M, Rassart E, Masse A, Simoneau L, Lafond $\mathrm{J}$ (2005) ERK1/2 and p38 regulate trophoblasts differentiation in human term placenta. J Physiol 566:409-423
33. Qiu Q, Yang M, Tsang BK, Gruslin A (2004) Both mitogenactivated protein kinase and phosphatidylinositol 3-kinase signalling are required in epidermal growth factor-induced human trophoblast migration. Mol Hum Reprod 10:677-684

34. Qiu Q, Yang M, Tsang BK, Gruslin A (2004) EGF-induced trophoblast secretion of MMP-9 and TIMP-1 involves activation of both PI3K and MAPK signalling pathways. Reproduction 128:355-363

35. Penney GC, Mair G, Pearson DW (2003) Outcomes of pregnancies in women with type 1 diabetes in Scotland: a national population-based study. BJOG 110:315-318

36. Casson IF, Clarke CA, Howard CV et al (1997) Outcomes of pregnancy in insulin dependent diabetic women: results of a five year population cohort study. BMJ 315:275-278 